\title{
Components Of Regional Income Convergence: Empirical Dimensions
}

\author{
Thomas A. Clark*
}

Numerous descriptive studies attest to the increasing parity of per capita personal incomes among states, but few address the separate contributions of each major income component within the aggregate process of relative convergence in the United States over the last half century. This paper, consequently, attempts empirically to assess the distinct dimensions of change in the spatial dispersion of personal income associated with labor (wage, salary, other labor, and proprietors' incomes), capital (property returns: dividends, interest and rents), and government transfers since 1930.

These components, of course, are interrelated. Labor returns enable personal investment in capital, and are influenced by capital expenditure patterns. Transfers involving retirement and disability payments may reflect prior participation in the labor force. The results of this study indicate substantial temporal and spatial variability in component relations, and raise further doubts regarding the efficacy of simple models of growth in interregional systems of advanced capitalist nations which stress labor returns but ignore the role of the federal "state" and spatial displacements involving capital returns and transfers $(3 ; 10 ; 12)$.

Following a brief survey of pertinent literature, temporal trends in interstate dispersions of each income component are examined. Subsequently, the cumulative contributions of income components to aggregate convergence and time-space variations in income composition are considered. Finally, component interactions are examined using crosssectional correlation analyses regarding static and dynamic component properties.

\section{CURRENT KNOWLEDGE}

The ensuing review of current knowledge concerning spatial income inequality in the United States is highly selective, stressing empirical dimensions of aggregate national trends. This much is known:

1. The relative dispersion of state per capita total personal incomes has been in secular decline since 1930. Williamson (22), who was among

*Graduate Division of Planning and Community Development, College of Design and Planning, University of Colorado at Denver, Denver, Colorado 80202. 
the first to demonstrate this, applied a coefficient of variation (standard deviation divided by the mean) to population-weighted state per capita incomes, noting a steady decline in the coefficient over the three decades following 1930. This trend, furthermore, has persisted at least through 1979 (Table 1, col. 1-unweighted coefficients).

2. While significant variations in regional living costs exist, the coefficient of per capita income variation still declines when state incomes are adjusted accordingly. ${ }^{1}$

3. The finding of increasing parity of state per capita incomes over time since 1930 is not method-specific. Four alternate inequality indices-relative entropy, Schutz, Herfindahl, and log-varianceyield compatible outcomes. ${ }^{2}$

4. Relative convergence, denoted by temporal decline in the coefficient of variation, does not dictate absolute convergence (which can be denoted by decline in the standard deviation of state incomes). Keuhn (8), in fact, observed that the standard deviation of constant dollar state per capita incomes actually increased during 1930-68. Subsequent analysis, however, indicates that absolute convergence is now also underway. Decennial standard deviations have declined since 1960 , through $1979 .^{3}$

Knowledge of trends in the dispersion of component incomes principally concerns labor income, and within this class, wage and salary incomes. They constitute approximately two-thirds of the national total today, and consequently have a major impact on aggregate income performance. Examining this category, Semple (13) reports an overall convergent trend in per worker regional incomes by major industry in the United States since the 1930's, excepting agriculture, based on the application of an information statistic to assess relative inequality. ${ }^{4}$

Likewise, Browne (1, p. 40) finds evidence of the interregional convergence of aggregate earnings per worker, at least over the last two decades. This is attributed both to the proportionate shift of workers out of low-wage farming in lagging regions (South, West North Central and Mountain States-regions defined by the Bureau of Economic Analysis (BEA), U.S. Department of Commerce) and, subsequently, to a convergent trend in nonfarm earnings per worker. Further convergence, it is argued, will depend primarily on the performance of nonfarm industries since relatively few workers remain in farming and the productivity of farm labor may be peaking. The convergence of nonagricultural earnings per worker, as Browne notes however, is not a simple function of the proportion of workers in manufacturing industries (which on average pay higher wages than do non-manufacturing industries within regions) or the internal composition of manufacturing (1, pp. 52-6). Earnings per worker within various types of manufacturing, and in non-manufacturing nonfarm industry as a whole, tend also to vary among regions complicating the effect of changes in industry mix, it is noted (1, p. 56). 
Further disaggregation within the inter-locking vectors of industry and occupation suggests not all sub-categories are equally prone to converge. Lande and Gordon (9), for example, assess temporal trends in wages per production worker man-hour among states in seventeen two-digit manufacturing industries. Using contingency tables rather than inequality indices, they observe that wages converged among states in only ten of the seventeen industries examined during 1947-67. That is, only ten conformed to the standard neoclassical expectation that wages will grow more rapidly in low- than in high-wage regions. Of course, industrial structure will continue to vary among regions, so aggregate per worker incomes will also vary despite the convergent trend in earnings per worker in single major industries (see also $4 ; 7$ ).

\section{THE DATA}

The income data employed in this study are derived exclusively from the Department of Commerce's Survey of Current Business. The specific issues from which data have been obtained are indicated in Table 1. At this writing a new benchmark income series is in preparation but not yet available for all years since 1929. While state personal income revisions (17) have been published using the 1976 benchmark for all years at least since $1958(18 ; 20)$, this study employs data tabulated according to earlier benchmarks (aside from Table 7) except for 1979, in order to insure some measure of consistency. Definitional and classification revisions according to the 1976 benchmark, it is noted, tended to diminish rental and farm proprietors' incomes. Constant dollar incomes in all time series are estimated using the "all item" consumer price index (21, Table 116). These data are not adjusted according to regional variations in living costs since regional indices have not been published for the period prior to 1967 .

Six income components are considered in the analysis. Wage and salary disbursements consist of all monetary remuneration of employees, whereas "other labor" income supplements wage and salary income and consists of employer contributions to private pension and welfare funds. These two sources account for 70 percent of total personal income in the United States currently. Proprietors' income is monetary income and income in kind of sole proprietorships and partnerships, both farm and nonfarm, and constitutes about seven percent of the total. Capital (ie. property) income, about twice that of proprietors', includes dividends, interest and rent, whereas transfer income derives from business and government payments to individuals. Transfer income, which about equals returns to capital, includes retirement (76 percent, 1978), public assistance (11 percent), unemployment (4 percent) and other payments (9 percent) (19, p.xvii).

Retirement and unemployment programs are financed by contributions to social insurance funds and general federal and state tax revenues, whereas public assistance (ie. income maintenance) programs are financed by general revenues. Over time these transfer components have had, and 
can be expected to continue to have substantial consequences for the relative income standing of regions. Not only is the share of national income derived from these sources increasing rapidly, but also their spatial distribution is highly responsive to variable state benefit standards (unemployment compensation and public assistance), interregional migrations of sub-populations eligible for transfers (welfare and retirement recipients) and regional economic conditions (unemployment compensation) (see also 11). In addition, public assistance and unemployment compensation may moderate cyclical swings in regional per capita incomes associated with national business cycles $(5 ; 11)$. Further specification of each income component may be found in the August 1977 issue of the Survey of Current Business, according to the 1976 benchmark (17), and in earlier volumes (see also 19).

\section{TRENDS IN INDIVIDUAL COMPONENTS}

During 1930-79, the coefficients of variation with respect to several major state per capita income components declined indicating increasing equality among states: total income, aggregate labor returns, capital returns and transfers (Table 1). Decennial coefficients declined regularly over all successive time intervals in the cases of total income and aggregate labor components, while both capital and transfer components' coefficients rose during 1930-40 and then entered a period of sustained decline. $^{5}$

\section{TABLE 1}

Coefficient of Variation of the Per Capita Components of Personal Income, Among States 1930-79

\begin{tabular}{cccccc}
\hline (N=48) & & & Type of Income & \multicolumn{2}{c}{ Nonlabor } \\
& & & \multicolumn{2}{c}{ Transfers } \\
Year & Total $^{\mathrm{a}}$ & Labor $^{\mathrm{b}}$ & Capital & Total & Adjusted $^{\mathrm{c}}$ \\
\hline 1930 & .381 & .332 & .663 & .282 & .282 \\
1940 & .355 & .314 & .715 & .382 & .390 \\
1950 & .247 & .236 & .462 & .209 & .226 \\
1960 & .208 & .200 & .362 & .182 & .224 \\
1970 & .148 & .154 & .235 & .140 & .194 \\
1979 & .119 & .129 & .222 & .130 & .196 \\
\hline
\end{tabular}

${ }^{a}$ Includes labor plus nonlabor income minus personal contributions to social insurance programs. Not adjusted to place of residence. Contiguous states only.

'Labor income includes wage, salary, other labor, and proprietors' incomes.

'Total transfers minus personal contributions to social insurance programs tabulated under total transfers (see text).

Source: Years 1930, 40, 50: U.S. (14); Year 1960:

U.S. (15); Year 1970: U.S. (16); Year 1979

U.S. (20). 
Rates of decrease in coefficients of variation, however, differ significantly among income components. Not unexpectedly, the labor component closely parallels the "total" per capita income component as does the capital component. But total transfer coefficients declined less rapidly and, when personal contributions to social insurance programs were subtracted from total transfers, the resulting "adjusted transfer" coefficients lagged still farther behind.

Absolute differences between coefficients of variation of per capita income components in single years suggest the character of underlying interregional income flows. Per capita capital coefficients, for example, exceeded those of both total and labor incomes in every year examined (Table 1). If the geographic distributions of capital investment and of per capita labor incomes are similar, as seems probable, then substantial interregional displacements of capital income would be expected since per capita labor incomes are more equally distributed than per capita capital incomes. State per capita labor and capital incomes, overall, have become progressively less positively cross-sectionally correlated over the last half century. High state per capita capital incomes would result as residents

\section{TABLE 2}

Frequency Distributions of State Per Capita Income In Constant Dollars ${ }^{\mathrm{a}}$, By Source, 1930, 1950 and 1979

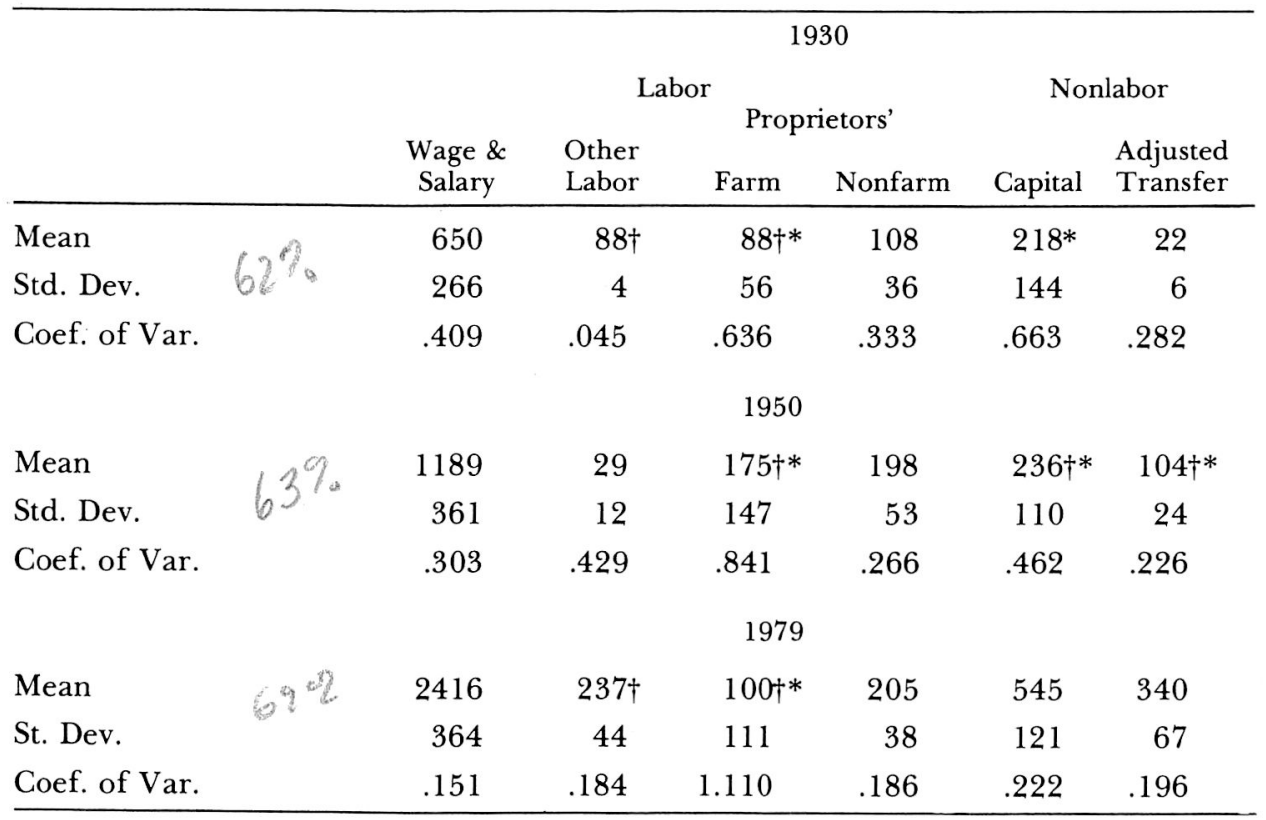

${ }^{a} 1967=100$, CPI, all items. The use of a national deflator affects both means and standard deviations proportionately and so does not affect the coefficient of variation.

†Kurtosis exceeds 1.0. None was less than -1.0 .

*Skewness exceeds 1.0. None was less than -1.0 .

Source: Author's calculations based on data used in Table 1. Consumer price indices: U.S. (21). 
extract capital returns generated both in their state of residence and elsewhere. Likewise, the gap between the coefficients of variation of total and adjusted transfers has widened over time. This, in turn, indicates the recipients of transfers are, in the aggregate, more uniformly distributed than those who pay directly into these programs through personal contributions to retirement and unemployment funds. In fact, a steady weakening of the positive cross-sectional correlation between state per capita gross transfers and per capita contributions to social insurance programs has occurred over the last four decades. At the same time, transfer recipients are likely to be less uniformly distributed than those currently contributing to transfers through general tax revenues. This would follow if aggregate per capita taxes and total per capita incomes are similarly distributed since total per capita incomes are now more equally distributed than transfers per capita.

Selected features of the frequency distributions of major per capita income components for 1930, 1950 and 1979 appear in Table 2. These indicate which distributional elements account for the coefficient shifts shown in Table 1. Wage and salary income, for example, had a declining coefficient of variation precisely because the constant dollar mean value increased more rapidly than did that of the standard deviation. Nonfarm proprietors' as well as capital and transfer components behaved similarly, while the coefficient of the farm element of proprietors' income actually increased. ${ }^{6}$ Significant departures from statistical normality are also indicated in Table 2. By 1979, these pertained to "other labor" income, whose kurtosis coefficient exceeded 1.0, indicating these per capita state incomes concentrated much nearer their mean value than they would have if normally distributed. ${ }^{7}$ Farm proprietors' incomes were similarly concentrated but tended to cluster below the mean value. ${ }^{8}$ Comparing conditions in 1930 and 1979, only the capital component converged both relatively and absolutely, whereas three others converged only relatively: wage and salary, nonfarm proprietors', and adjusted transfer incomes.

\section{INTERSTATE VARIATION IN INCOME COMPOSITION}

On average, the income composition of the states is undergoing a number of significant shifts (Table 3). Comparing conditions in 1930 and 1979 , the mean value of the percentage of state incomes derived from capital and transfers combined has remained almost constant, though the mean percentage contribution of capital income has fallen, while that for adjusted transfers has risen, more than off-setting the capital loss. At the same time, the comparable mean state percentages devoted to both wage and salary and "other labor" incomes increased, even as both proprietor categories experienced percentage losses. Overall, the mean percents of state incomes derived from all labor sources and therefore from capital plus transfer sources have remained almost constant over the last half century. ${ }^{9}$ That is, "income mix" has not changed significantly during these years despite secular shifts in industrial structure and in demographic 
composition. Of course, the composition of incomes within each of these major components has changed significantly over the last half century but relative income gains in one component have tended to compensate for losses in others.

In sum, the variation of income composition among states appears not to be substantial. In 1979, in all instances other than farm proprietors' incomes, the standard deviation of the percentage of total state income derived from given sources was less (often much less) than 25 percent of the mean value over all states. ${ }^{10}$ It is concluded that interstate variation in per capita incomes may be less a product of differences in "income mix," than of "effective productivities" (i.e. component income divided by total population) associated with the income-generating capacities of workers, owners of capital, and transfer-eligible populations. ${ }^{11}$ Over time, however, both "income mix" and differential aggregate per capita incomegenerating capacities have combined to promote overall per capita income convergence. ${ }^{12}$

\section{INTERACTIONS AMONG COMPONENTS}

Income components clearly must interact both within and among regions. Two approaches are employed in this final segment to examine

\section{TABLE 3}

Frequency Distribution ${ }^{\text {a }}$ of Each Source of State Personal Income, Given as a Percent of Total, Among States, 1930, 1950 and 1979

\begin{tabular}{|c|c|c|c|c|c|c|}
\hline & \multicolumn{6}{|c|}{1930} \\
\hline & \multirow{3}{*}{$\begin{array}{l}\text { Wage \& } \\
\text { Salary }\end{array}$} & \multicolumn{3}{|c|}{ Labor } & \multicolumn{2}{|c|}{ Nonlabor } \\
\hline & & & \multicolumn{2}{|c|}{ Proprietors' } & & \multirow{2}{*}{$\begin{array}{l}\text { Adjusted } \\
\text { Transfer }\end{array}$} \\
\hline & & Labor & Farm & Nonfarm & Capital & \\
\hline Mean & 58.86 & .72 & 9.89 & 10.10 & 18.37 & $2.07 \dagger^{*}$ \\
\hline \multirow[t]{2}{*}{ Coef. of Var. } & .08 & .28 & .69 & .16 & .30 & .53 \\
\hline & \multicolumn{6}{|c|}{1950} \\
\hline Mean & 60.99 & $1.51 \dagger^{*}$ & $9.65 \dagger^{*}$ & 10.35 & $11.83 \dagger^{*}$ & 5.67 \\
\hline \multirow[t]{2}{*}{ Coef. of Var. } & .12 & .33 & .83 & .15 & .24 & .28 \\
\hline & \multicolumn{6}{|c|}{1979} \\
\hline Mean & 62.77 & $6.16 \dagger$ & $2.65 \dagger^{*}$ & 5.37 & 14.09 & 8.97 \\
\hline Coef. of Var. & .07 & .14 & 1.11 & .17 & .16 & .22 \\
\hline
\end{tabular}

aSame figures result when using either current or constant dollars and either total or per capita incomes.

$\dagger$ Kurtosis exceeds 1.0. None was less than -1.0 .

*Skewness exceeds 1.0. None was less than -1.0 .

Source: Author's calculations based on data used in Table 1. 
gross interactions in the form of statistical associations among components. The first addresses pairwise correlations of per capita components across states in 1930, and again in 1979 (Table 4). While pairwise correlations among absolute, "non-per capita" (ie. income not divided by population) component incomes are uniformly high in both years (not shown), the corresponding correlations of per capita components are not. While wage and salary, other labor and capital incomes per capita were indeed highly correlated with total income per capita in 1930 and 1979, total transfers and nonfarm proprietors' incomes were so only in 1930. Not unexpectedly, farm proprietors' incomes were so in neither year, given spatial variations in agricultural endowments.

The differences between corresponding per capita and non-per capita (not shown) matrices are wholly attributable to the distributional features of population itself. Its statistical impact, however, is somewhat ambiguous. Since the correlation coefficients in both matrices associated with total income were about equally high (in both 1930 and 1979), it might then be concluded that population would necessarily be highly correlated with total income as well. Such an inference, however, is correct only with respect to the association between population and total income (both years). These coefficients approach unity, but those for the association between population and per capita total income are considerably lower (Table 4).

\section{TABLE 4}

Cross-sectional Correlations ${ }^{\mathrm{a}}$ of State Per Capita Income Components, $1979^{\mathrm{b}}$ and $1930^{\mathrm{c}}$

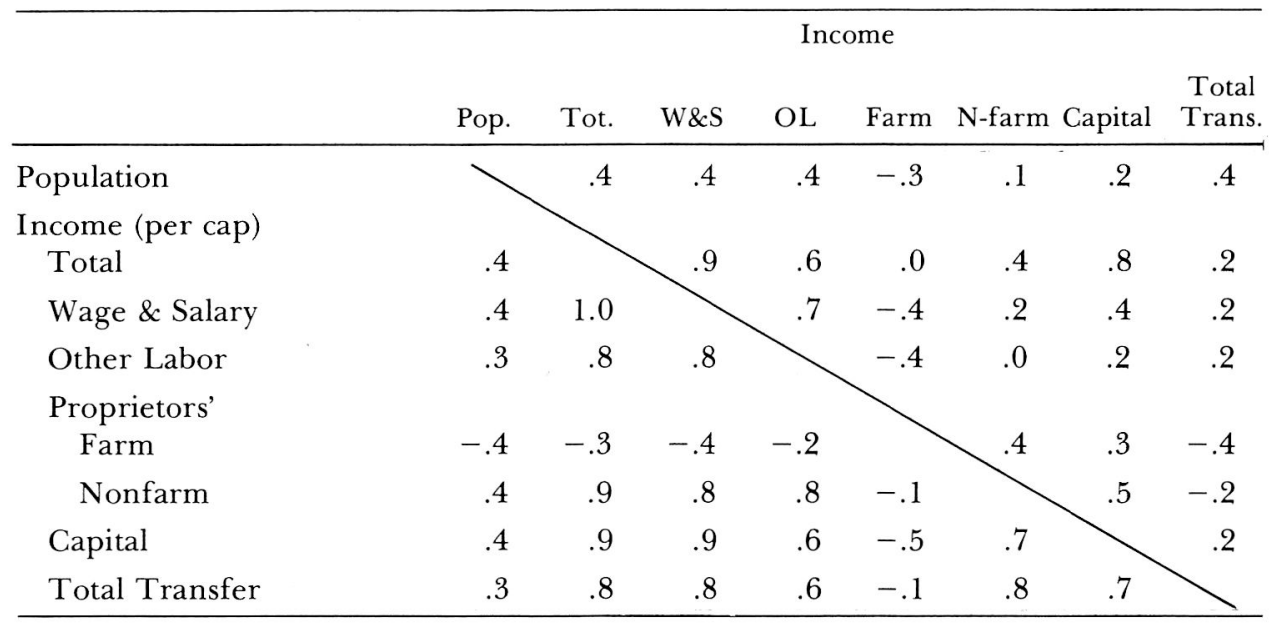

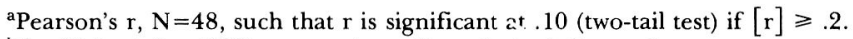

${ }^{\mathrm{b}}$ Coefficients for 1979 appear above the principal diagonal.

${ }^{\mathrm{c}}$ Coefficients for 1930 appear below the principal diagonal.

Source: Author's calculations based on data in Table 1 . 
To assess the association over time between population and total income in each component, the correlations between percent changes in population and percent changes in each component have been determined for 1930-50, and again for 1950-79 (Table 5). Not only was there no substantial association between population and per capita income components in 1930 (Table 4) but, in addition, the percent change in state population during 1930-50 was not highly correlated with percentage changes in any of the state income components occurring simultaneously. Further, in 1950 , population and per capita income components were again only weakly linked (not shown), but during 1950-79 the percent change in state population was in fact highly correlated with percentage changes in all components except farm proprietors' income (Table 5).

In sum, percentage change in population was highly correlated with percentage change in total incomes during 1950-79 but not 1930-50. During the more recent period it appears that either people were drawn to states in proportion to state capacities to generate additional income or that the forces which distribute incomes among states became more directly attuned to the population itself. The latter explanation has particular appeal since federal social entitlement programs expanded significantly after 1950 , hence the high association between changes in total transfers and population during 1950-79. These would, in turn, induce secondary growth in local, non-basic industries. In addition, populationoriented service-performing segments of the national post-industrial

\section{TABLE 5}

Correlates $^{\mathrm{a}}$ of Percent Change in Population During 1930-50, and 1950-79

\begin{tabular}{lcc}
\multicolumn{1}{c}{$\begin{array}{c}(\mathrm{N}=48) \\
\text { Percent Change } \\
\text { in Attribute } \\
\text { Same Period }\end{array}$} & \multicolumn{3}{c}{$\begin{array}{c}\text { Percent Change in } \\
\text { Population }\end{array}$} \\
\hline Total Income & $1930-50$ & $1950-79$ \\
Wage \& Salary & .47 & .92 \\
Other Labor & .49 & .90 \\
Proprietors' & .09 & .75 \\
$\quad$ Farm & & .20 \\
$\quad$ Nonfarm & .02 & .79 \\
Capital & .54 & .73 \\
Transfers & .38 & .93 \\
$\quad$ Total & .48 & .89 \\
$\quad$ Adjusted & .43 & .78 \\
Social Insurance & .09 & \\
\hline
\end{tabular}

aPearson's $\mathrm{r}$, such that $\mathrm{r}$ is significant at .10 (two-tail test) if $[\mathrm{r}] \geqslant .24$.

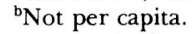

Source: Author's calculations based on data in Table 1. 


\section{TABLE 6}

Cross-sectional Correlations ${ }^{\mathrm{a}}$ of Percentage Changes

in State Per Capita Income Components, $1930-50^{\mathrm{b}}$ and $1950-79^{\mathrm{c}}$

\begin{tabular}{lccccccc}
\hline $\begin{array}{c}\text { Percent } \\
\text { Change in } \\
\text { Component }\end{array}$ & Tot. & W\&S & OL & Farm & Nonfarm & Capital & Total \\
Income Component & Trant \\
\hline Total & & .9 & .8 & .2 & .8 & .7 & .4 \\
Wage \& Salary & .8 & & .9 & .3 & .7 & .8 & .3 \\
Other Labor & .5 & .6 & & .3 & .6 & .7 & .3 \\
Proprietors' & .5 & .1 & .1 & & .1 & .3 & -.1 \\
$\quad$ Farm & .9 & .7 & .4 & .5 & & .6 & .4 \\
$\quad$ Nonfarm & .8 & .6 & .3 & .5 & .8 & .6 & .2 \\
Capital & .6 & .7 & .3 & .1 & .6 & .3 & \\
Total Transfer & & & & & &
\end{tabular}

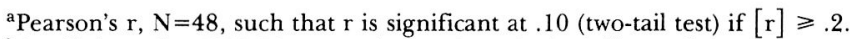

${ }^{\mathrm{b}}$ Coefficients for 1930-50 appear below the principal diagonal.

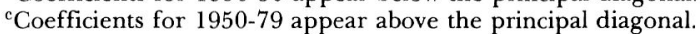

Source: Author's calculations based on data in Table 1.

economy also expanded rapidly in recent decades, providing further substantive support for this empirical linkage.

A second means for examining the associations among income components involves consideration of the pairwise relationships among percentage changes in per capita components during 1930-50 and 1950-79 (Table 6). In each interval, change in population was only weakly correlated with changes in per capita components (not shown), but many of the component changes were highly correlated in both periods. Percent change in wage and salary income, in particular, was highly correlated with percent change in other labor, nonfarm proprietors' and capital per capita incomes in both intervals, but with total transfers only during 1930-50.

While the correlations among percentage changes in the per capita labor components (Table 6) are, on their face, consistent with earlier commentary, the capital and transfer components require further examination. The high coefficients pertaining to per capita capital incomes in both intervals are consistent with high resident saving and investment potential arising from high per capita labor incomes. Of course, not all of this surplus would have been invested in the same region in which it was generated. Total transfer coefficients associated with both total, and wage and salary per capita incomes, on the other hand, were considerably lower during 1950-79 than 1930-50 (Table 6). The shift between periods tends to suggest change over time in the nature of the subpopulations receiving transfers as well as increasing disparity in the proportionate presence of these subpopulations among states. 
Overall, the rates of change in income components are not randomly variant over space (see also $4 ; 5 ; 11$ ). To examine the geographic distribution of growth rates, the percentage increase in each major component income has been estimated for each multi-state BEA region for 1929-59 and 1959-79. While contiguous regions tend to exhibit similar rates, there also exists a persistent dichotomy between the regions of the northern and central tier on one hand and the southern and western on the other. Regarding every component examined, there is greater variation in growth rates between these large regions than within either (4).

Each growth rate, consequently, is reported for these two multi-regional groupings only and is presented as a percentage of the U.S. equivalent (Table 7). Two conclusions follow. First, the so-called "frostbelt-sunbelt" dichotomy is not a new phenomenon. All major income components examined grew faster in the southern-western tier than in the northerncentral tier not only during 1959-79 but also 1929-59 (Table 7). Further, in all instances except farm income, component growth rates in the southern-western tier exceeded those of the northern-central tier by a greater amount in the earlier time interval. Second, total labor, capital and transfer incomes have had similar growth rates in single regions and time

\section{TABLE 7}

Percent Change in Population and Income by

Source, as a Percentage of the U.S.

Equivalent, by Region, 1929-59 and 1959-79

$$
\text { (Index: U.S. }=100)
$$

\begin{tabular}{|c|c|c|c|c|c|c|}
\hline \multirow[b]{3}{*}{ Regions $^{\mathrm{a}}$} & \multicolumn{2}{|c|}{ Aggregate Income ${ }^{\mathrm{b}}$} & \multicolumn{4}{|c|}{ Labor and Proprietors' } \\
\hline & & Per & & Nonfarm & & Total \\
\hline & Total & Capita & Total & Total Manuf. & Farm & Capital Transfers Pop \\
\hline
\end{tabular}

(1929-59)

North and

$\begin{array}{lllllllllll}\text { Central } & 84 & 91 & 86 & 84 & 86 & 85 & 80 & 84 & 91\end{array}$

South and

West

143

127

136

$147 \quad 165$

$99 \quad 170$

141

127

North and

Central

$\begin{array}{ll}87 & 97\end{array}$

(1959-79)

South and

West

$122 \quad 112$

$85 \quad 85$

87

a“North and Central" includes these BEA regions: New England, Mideast, Great Lakes and Plains. "South and West" contains the following BEA regions: Southeast, Southwest, Rocky Mountain and Far West. The latter excludes Alaska and Hawaii before 1959.

bTotal income is adjusted by place of residence.

Source: Author's calculations based on data in Friedenberg (4, Table 2) and U.S. (20). 
periods except for the southern-western tier during 1929-59. In summary, the absolute difference between regions in growth rates is narrowing.

\section{CONCLUSIONS}

State per capita personal incomes have been engaged in a secular process of relative convergence for five decades and in recent years aggregate absolute disparity has also begun to diminish. The major income components have not contributed equally to these processes, though per capita labor, capital and transfer incomes have all converged significantly. Variation in total per capita income among states and over time, it has been demonstrated, is statistically wholly attributable to spatial and temporal differences in "income-mix" (ie. the distribution of total income among components) and "effective productivities" (ie. income component divided by total regional population) associated with the income-generating capacities of each income component. Further disaggregation would indicate to what degree interstate differences in effective productivity can be attributed to variations among states in the proportionate presence of workers, owners of capital and transfer-eligible subpopulations. ${ }^{13}$

Broadly, and by way of summary, a region's total per capita income depends on just two factors: total population and total income. Each, however, is influenced by the other and both are internally complex. Population, in the aggregate, depends on migration among regions and natural increase and both are influenced by relative regional economic performance. Further, these demographic dynamics plus aging produce the age structure of the regional population at any point in time; this structure in turn governs the size of the labor force as well as the retirement-aged and, less directly, other transfer-eligible subpopulations. Capital ownership would be a complex function of earnings and other factors. At the same time, total personal income will depend on both the number of persons associated with each distinct income component and subcomponent and the level of income per person participating in each. These, in turn, will be influenced by flows of resources among industrial sectors, aggregate income components (labor, capital and transfers) and regions.

In the short-run, during which population is more or less stable, autonomous intra-regional shifts of workers from lower to higher wage industries and of personal income composition from lower to higher per capita income components will increase per capita incomes, ${ }^{14}$ as will autonomous increases in per capita payments in any individual aggregate income component (see also 1; 2). Shifts to lower paying components would produce the opposite result. In the longer-run, regional conditions may influence interregional flows of both capital and people leading to either the reinforcement or the reversal of the prior trend. Further, the movement of people among industrial sectors and regions and shifts in individual income composition may ultimately affect payments received per person in each sector, component and region. For example, shifts of 
workers to higher paying industrial sectors and regions may, under some circumstances, diminish wages in these sectors and regions. Similarly, increases in the proportion of the population retired or unemployed may diminish associated transfers. As a result, the effect of any realignment between population and resources can be expected to have potentially substantial long-run consequences due to shifts in associated per capita payments.

The development of adequate income-predictive regional models will necessarily have to address the separate though partially interdependent processes governing the spatial distribution of each component of income. Most simple regional growth models stress labor returns. But it has been shown that these are not highly correlated with all other components among states, either statically (1979) or with respect to proportionate changes (1930-50 and 1950-79). They are, however, the largest single contributor to total personal income. Further disaggregation of the individual avenues of income-generation would also offer the prospect of more adequately portraying the role of the federal "state" and therefore aid in assessing the spatial impacts of federal policies.

\section{FOOTNOTES}

1. This determination is based on a comparison of coefficients of variation in state per capita personal incomes in 1929 and 1976, using income data adjusted to regional living cost indices estimated by Williamson (23). Income data employed in the current analysis, however, are not adjusted to regional CPI's. This is because a consistent time-series of regional CPI's exists only for the years since 1967 (21, Table 123). It may eventually be possible to reconstruct indices for prior years, at least as far back as 1935, by applying appropriate weightings to published indices for select major cities according to Department of Labor representatives.

2. These alternate indices are identified by Gaile (6). All were employed in a comparative-statics framework, and advanced toward maximum equality during 1930-79.

3. These standard deviations are estimated using the data identified in Table 1. They are: .484 (1960), .470 (1970), and .458 (1980).

4. Semple (13) estimated "per capita" regional income inequality by major industry. Per capita incomes were calculated by dividing wage and salary disbursements given in the Survey of Current Business by total employment by industry, provided in Employment and Earnings.

5. Coefficients of variation have also been estimated for each year indicating the cumulative contribution to the convergence process of each unearned component. To do so, coefficients were first estimated for per capita total labor incomes in each year, then recalculated after adding capital incomes and, subsequently, both total and net transfers. The results, anticipated by Table 1, show capital incomes diminish equality in every year but at a temporally decreasing rate. Transfers (total and net) increase equality in all years when added to total labor plus capital incomes.

6. This is consistent with Semple's (13) finding of per capita agricultural income divergence.
7. Kurtosis, or "peakedness," is measured by a coefficient allowing comparisons of empirical distributions relative to the normal. If greater than zero, the distribution is more peaked than is the normal but, if less than zero, it is less peaked.

8. Skewness is deviation from symmetry. Values are clustered beneath the mean when the coefficient exceeds zero, and above the mean when less than zero.

9. Friedenberg (4, Table 3) reports the percentage distribution of personal income by region at similar time intervals.

10. The standard deviations of each per capita component expressed as a percent of total per capita income by state in 1979 are, in descending order: wage and salary $(4.39 \%)$, farm proprietors' $(2.94 \%)$, capital $(2.25 \%)$, transfers (adjusted) (1.97\%), nonfarm proprietors' (.91\%) and "other labor" income $(.86 \%)$.

11. The cross-sectional correlations of non-per capita component incomes are uniformly high, excepting those related to farm proprietors, in each year examined but those for per capita correlations are not.

12. "Aggregate income-generating capacity" in individual states is simply the per capita income associated with each individual income component. These "effective" productivities differ from actual productivities. The latter would be given by the ratio of a state's income in a single component to the size of the subpopulation associated with this same component. Variations among states in effective productivities will differ from those involving actual productivities.

13. See footnote 12. Interstate variations in effective productivity (ie. component income divided by total population) can, of course, exist even when actual income-productivities (ie. component income divided by the size of the subpopulation receiving this income) do not. Differences in the patterns of actual 
and effective productivity in single components will, in fact, exist so long as the respective subpopulation is not uniformly proportionate to total state population. In practice, since the subpopulation associated with capital and transfer components will overlap those in labor components, it may be very difficult to specify all component subpopulations empirically.

14. For example, Browne notes that by 1960 employment ratios (total workforce divided by total population) tended to reinforce the differences among BEA regions in amounts earned per worker. Employment ratios in that year were found to be directly correlated with both total per capita income and earnings per worker. By 1976, however, these cross-sectional correlations had apparently disappeared since employment ratios rose in lower income regions and fell in the Mid-Atlantic states between 1960 and 1976 (2, p. 56). Still, in any single region, decreases in the employment ratio due to autonomous increases in unemployment or the percentage of the population retired and to autonomous decreases in labor participation rates will diminish total per capita income so long as average earnings per worker exceed average nonlabor incomes of persons shifting out of the workforce.

\section{REFERENCES}

1. Browne, Lynn. "Narrowing Regional Income Differentials," New England Economic Review (Federal Reserve Bank, Boston) (September/October 1980): 35-56.

2. Browne, Lynn. "Narrowing Regional Income Differentials: II," New England Economic Review (Federal Reserve Bank, Boston), (November/December 1980): 40-59.

3. Clark, Thomas A. "The Role of the State in Regional Development" in Institutions and Geographical Patterns, edited by Flowerdew, R. London: Croom Helm, 1982, Ch. 6, pp 169-208.

4. Friedenberg, Howard L. "Regional Differences in Personal Income Growth, 1929-77," Survey of Current Business, 58, 10 (October 1978): 27-31.

5 . and Bretzfelder, Robert. "Sensitivity of Regional and State Nonfarm Wages and Salaries to National Business Cycles, 1948-79," Survey of Current Business, 60, 5 (May 1980): 15-27.

6. Gaile, Gary L. "Effiquity: A Comparison of a Measure of Efficiency with an Entropic Measure of the Equality of Discrete Spatial Distributions," Economic Geography, 53 (1977): 265-82.

7. Graham, Robert E., Jr. "Factors Underlying Changes in the Geographic Distribution of Income," Survey of Current Business, 44,4 (April 1964): 14-32.

8. Keuhn, John A. "Income Convergence-A Delusion," The Review of Regional Studies, 2,1 (Fall 1971): 41-51.

9. Lande, Paul S. and Gordon, Peter. "Regional Growth in the United States: A Re-examination of the Neoclassical Model," Journal of Regional Science, 17,1 (1977): 61-9.

10. Miernyk, William H. "A Note on Recent Regional Growth Theories," Journal of Regional Science, 19,3 (1979): 303-8.

11. Renshaw, Vernon and Friedenberg, Howard L. "Transfer Payments: Regional Patterns, 1965-75," Survey of Current Business, 57,5 (May 1977): 15-19.
12. Richardson, H. W. "Empirical Aspects of Regional Growth in the United States," The Annals of Regional Science, 8,2 (1974): 8-23.

13. Semple, R. Keith. "Regional Development Theory and Sectoral Income Inequalities" in Geographical Horizons, edited by Odland, J. and Taaffe, R. N. Dubuque: Kendall/Hunt, 1977, pp. 45-63.

14. United States Department of Commerce, Office of Business Economics. "Personal Income of States Since 1929," Supplement to the Survey of Current Business, 1956.

15. Survey of Current Business, 42,8 (August 1962): Tables 6-61 (Coleman).

16. United States Department of Commerce, Bureau of Economic Analysis. Survey of Current Business, 53,8 (August 1973): Tables 6-61 (Bretzfelder).

17. "State Personal Income Revisions, 1971-76," Survey of Current Business, 57,8 (August 1977): $15-64$.

18. . "State Personal Income 1958-78," Survey of Current Business, 59,8, Part II (August 1979): 28-55.

19. . "Volume I: Summary by Major Source for All Regions, States, SMSA's, BEA Economic Areas," Local Area Personal Income 1973-78, (July 1980)

20. - Survey of Current Business, 6,8 (August 1980): Table 3 (Regional Economic Measurement Division)

21. United States Department of Labor, Bureau of Labor Statistics. Handbook of Labor Statistics, 1978. Bulletin 2000. Washington, D.C.: G.P.O., 1979.

22. Williamson, Jeffrey G. "Regional Inequalities and the Process of National Development," Economic Development and Cultural Change, 13 (1965): 3-45.

23. . "Unbalanced Growth, Inequality and Regional Development." Presented at the L.B.J School of Public Affairs, University of Texas, Austin, September 1977. 